\title{
The Influences of Parasocial Relationship and Sources Credibility in Promoting Sustainable Fashion in Social Network Sites
}

\author{
Nornajihah Nadia Hasbullah, Zuraidah Sulaiman, Adaviah Mas'od
}

\begin{abstract}
Fashion industry is the second most polluted industry in the world that has caused social and environmental issues. Pointing to the fact, sustainable fashion has been designed to reduce pollution and to improve working conditions in the industry. Concurrently, many consumers have claimed that they are concerned about the impact of major fashion brands on the planet. However, beyond the concerned, the market share produced on this fashion concepts are still lagging. In reaching potential consumers, advertisement via social network sites (SNS) appears to be the most effective medium to reach them. Due to this reason, this study designed the most persuasive ways of promoting sustainable fashion advertising. By engaging the Persuasion Knowledge Model (PKM), this conceptual paper demonstrates the relationships between parasocial relationship, sources credibility, and sustainable fashion consumption. This study proposes three hypotheses based on the growth of sustainable fashion within the Malaysian context. As this study will involves with quantitative analysis, the researchers will employ the PLS software for data analyses in future. Although the sustainable fashion scene in Malaysia is still slow, its growth is promising. The findings can be leveraged to gain deeper understanding on how to create effective digital advertising with the implementation of persuasive knowledge, parasocial relationships, and sources credibility. Accordingly, the study outcomes contribute to various practical implications that may be beneficial for marketing, policy making, and non-governmental action aimed at stimulating sustainable fashion consumption from a dyadic perspective.
\end{abstract}

Keywords : Persuasion Knowledge Model, Parasocial Relationships, Sources Credibility, Social Network Sites Advertising, Sustainable Fashion Consumption.

\section{INTRODUCTION}

Globally, the fashion industry has been reckoned as the second contributor to the pollution in the world. The ignorance of social welfare and poor working conditions

Revised Manuscript Received on February 05, 2020.

* Correspondence Author

Nornajihah Nadia Hasbullah*, Azman Hashim International Business School (AHIBS), Universiti Teknologi Malaysia (UTM), 81310 Skudai, Johor, Malaysia, najihahnadya@yahoo.com.my

Zuraidah Sulaiman, Azman Hashim International Business School (AHIBS), Universiti Teknologi Malaysia (UTM), 81310 Skudai, Johor, Malaysia.

Adaviah Mas'od, Azman Hashim International Business School (AHIBS), Universiti Teknologi Malaysia (UTM), 81310 Skudai, Johor, Malaysia.

(C) The Authors. Published by Blue Eyes Intelligence Engineering and Sciences Publication (BEIESP). This is an open access article under the CC BY-NC-ND license (http://creativecommons.org/licenses/by-nc-nd/4.0/) have led to the disastrous collapse of the Bangladeshi production building Rana Plaza in 2013 [1-2]. The excessive environmental pollution in the garment manufacturing industry is caused by the disproportionate use of chemicals, thus creating more sustainability issues in the clothing industry [3-4-5]. Indeed, consumers are increasingly asking for sustainable fashion, although their purchasing behavior may be inconsistent with their claims [3-6]. In order to overcome this problem, the way and the medium used to communicate is crucial in changing the perception of sustainable fashion [3]. As communicating sustainable fashion is challenging [7], the most prominent tool to use for digital advertisement is the social network sites (SNS) [8-9].

In the context of Malaysia, sustainable fashion scene is slow but promising. This has been proven with the increasing number of sustainable fashion entrepreneurs joining this niche market, including Real-M, Kanoe, Zibossa, and Nukleur Wear. Simultaneously, the global non-profitable organisations, namely fashion revolution campaigns, have already made their move to advocate sustainable, ethical, and fair fashion. The Fashion Revolution movement has already spread across over 100 countries worldwide, including Malaysia. This movement aims to unite the fashion industry and ignite this positive revolution throughout the world. The government has also shown full support by sharing the same standard of green products with the rest of the world. Malaysia has joined the urgent call for action for all countries by signing the agreement involving 193 UN Member States to achieve 17 Sustainable Development Goals in September 2015 [10]. The newly implemented 2030 agenda emphasizes on the holistic approach to achieve sustainable development for all. In promoting sustainable fashion globally, Michelle Yeoh has been assigned as the official ambassador to promote this positive movement across the world.

In a similar vein, this study determined the relationships of persuasion knowledge in SNS advertising, with parasocial relationships and sources credibility in influencing sustainable fashion consumption. The remainder of this article is structured as follows. The next section describes the problem statement. Section 3 briefly explains the significance of the study, followed by outline of research questions and objectives in Section 4. Next, Section 5 introduces the theoretical framework of this study, which is based on Persuasion Knowledge Model (PKM) [23]. Additionally, it summarizes the specific extant literature on sustainable consumption and formulation of hypotheses. 
Moving on, Section 6 describes the methodology undertaken in this study. Section 7 summaries the study, and highlights the important findings. The final section addresses the shortcomings of this study and presents insights into future research in the area of sustainable fashion.

\section{PROBLEM STATEMENT}

Since past few years, interest towards sustainable products and services has grown favorably. [11] found that about 70 percent of customers were willingness to pay more for brands that invest in sustainability. The market share of sustainable product is still lagging as not all customers put their talk into their final action [12]. Reflecting on this, effective advertisement needs to convey information to create awareness and simultaneously, the final consumption. As social network sites (SNS) advertising is preferable nowadays, this study explored the promotion of this kind of fashion by considering persuasive ways.

In particular, research gap still exists on improving sustainable fashion advertising, as well as to better understanding the target audience [13-14-15-16-17-18]. In doing so, this present study sought to address this gap by uniting the most persuasive ways of promoting sustainable fashion advertising using the SNS medium. In keeping with this positive movement, this study aims to understand the relationships between parasocial relationships, sources credibility, and sustainable fashion consumption.

\section{SIGNIFICANCE OF STUDY}

Promoting sustainable fashion through SNS advertising is significantly important to ensure the wider spread of information regarding this positive fashion. The involvement of SNS advertisement makes information more accessible and reachable to potential consumers. Overall, this study significantly contributes to industry players, consumers, and government in shaping the future of sustainable fashion in Malaysia.

\section{A. Industry Players}

The persuasive knowledge about SNS advertising structure can also be adopted by fashion retailers to capture the hearts of the target market, increase brand loyalty, and generate more profit. It is not easy to assimilate sustainability in the shopping culture and habit in Malaysia, but it is not impossible with great effort.

\section{B. Customers}

The integration of parasocial relationships and sources credibility can make consumers more interested to explore further information about sustainable fashion. you.

\section{Government}

The development of sustainable fashion in Malaysia is still in infancy stages. Hence, the level of awareness has been increasing and has a huge potential in business [19]. Malaysia's sustainable fashion scene is still doubtful, but with full support by the government and industry, investments in green growth initiatives could be encouraged, resulting in positive outcome for the future of this positive movement.

\section{RESEARCH QUESTIONS AND RESEARCH OBJECTIVES}

\section{A. Research questions}

Prior studies and the identified literature gap have motivated this study to explore the following:

1) How to design SNS advertisement in a persuasive way (based on Persuasion Knowledge Model) when promoting sustainable fashion product in Malaysia?

2) Do parasocial relationship and sources credibility help to enhance persuasion knowledge and influence sustainable fashion consumption in Malaysia?

\section{B. Research Objectives}

This study aims to design SNS advertising based on persuasive knowledge, with the integration of parasocial relationships and sources credibility in influencing sustainable fashion consumption in Malaysia.

\section{THEORETICAL FRAMEWORK, LITERATURE REVIEW AND HYPOTHESES DEVELOPMENT}

\section{A. Theoretical Framework}

The PKM can be translated as 'knowledge about the tactics and intentions of advertising' [20-21]. This knowledge involves the abilities to identify and understand persuasive intentions of advertising and to engage in an effective way [22]. [23] stated that consumers need to have the ability to diagnose and understand the tactics of advertising. Marketers will use the information to make paradigm changes to consumers' attitude, belief, and behavior. In precise, customers can use their persuasion knowledge to determine when a salesperson is attempting to influence or manipulate a situation to achieve his/her own goals [24].

\section{B. Literature Review}

Define abbreviations and acronyms the first time they are used in the text, even after they have been defined in the abstract. Abbreviations such as IEEE, SI, MKS, CGS, sc, dc, and rms do not have to be defined. Do not use abbreviations in the title or heads unless they are unavoidable.

- SNS Advertising: Recently, there has been a spark of interest in online social media, including Facebook, Twitter, YouTube, and Instagram [25-26-27]. According to [28], the rapid development and diffusion of SNS have greatly changed the way people develop relationships and exchange information, including a change in the relationship between consumers and companies [29]. The SNS enables users to communicate with real-life friends and other people who share their interests in the virtual environment [30]. Indeed, attitude toward personalized advertising can predict online purchase [31].

- Sustainable Fashion Consumption: Sustainable consumption is consumption that supports the ability of present and future generations to meet their material and other needs, without causing irreversible damage to the environment or loss of function in natural systems. This 'umbrella term' combines meeting needs, improved quality of life, increasing the use of renewable energy 
sources, minimizing waste, and looking at the entire product lifecycle [32]. It is essential to discover sustainable consumption on sustainable apparel, as this fashion is a key contributor to a huge potential market [33].

Most of the sustainable fashion consumers have demonstrated positive consumption based on prosocial behavior, empathy, and high level of agreeableness [17].

- Persuasion Knowledge Model (PKM): Persuasion Knowledge Model [23] was developed based on three elements, namely topic knowledge, customer knowledge, and persuasion knowledge.

- Topic Knowledge: Topic knowledge refers to one's existing knowledge about the given persuasion situation [23]. The topic knowledge of this study is related to the concept of sustainable fashion. This positive concept was first internationally coined during the Rio Earth Summit in 1992 [34]. Sustainable fashion can be translated as a system that promotes ecological integrity, social quality, and human flourishing through products, actions, relationships, and practices of use [35]. This concept blankets all aspects, including a myriad of terms labelled with recycled, organic, vintage, vegan, artisan, locally made, custom-made, and fair-trade certification [36-1-38]. [39] asserted that the implementation of sustainable fashion does not mean we need to stop purchasing and wearing our favorite collection, but instead, to spend more in something that can be worn for a longer time. Within the context Malaysia, [40] stated that sustainable fashion should be practiced starting from fashion manufacturers. Fashion players need to share complete information and interesting facts to spurge interest among customers towards sustainable fashion.

- Customer Knowledge: Agent knowledge is knowledge related about a company's current management, practice concepts, current and past marketing, as well as social activities. Concurrently, many sustainable customers want their consumption reflected based on their subjective terms [41]. Most of their consumptions are influenced by individual interests to enhance social status, instead of collective interests [42]; [43]. Practically, customers will select fashion based on their preferences instead of weighing in sustainability issues from their consumption. Some consumers may refuse this positive fashion as they still perceive it as an old-fashioned item [44].

On the contrary, [3] claimed that sustainable clothing has turned into an emerging trend to date, and this notion is evidenced by the increasing number of entrepreneurial start-ups penetrating this niche market. The formation of newer design strategies, including customization and modularity [45], has made sustainable fashion to look more attractive. Concurrently, consumers have begun reconsidering priorities and gradually questioning values, including sustainability and transparency, which have lead some researchers to label them as a new consumerism concept [46]. Transparency is a vital element that turns a brand into a role model for other brands [47].
Considering this point, most of the market potentials are sustainability-minded and focus more on developing self-enhancement motives [41]. It was found that consumers would focus more on developing personal benefits of sustainable fashion, including skin tolerance of organic fabrics and self-esteem gained by helping the needy society [ 48, 36]. [49] added that consumers associate attributes, such as durability, with sustainable clothing.

Meanwhile, [42] and [36] asserted that in promoting sustainable clothing, an entrepreneur needs to consider aspects other than sustainability element. According to [50], value-for-money and epistemic value are the two predominant value dimensions behind the general green consumption in Malaysia. However, many customers are still unaware about related information regarding existing offerings or where to purchase sustainable clothing [3]. Consumer knowledge about sustainability practices is still low in Malaysia. Thus, marketers can creatively attract them

by using other consideration aspects. One viable way to reach customers is through the involvement of SNS platform by disclosing digital celebrities in commercial content to influence sustainable fashion consumption [51].

- Persuasion Knowledge: Persuasion knowledge allows consumers to infer underlying motives and intentions behind these crisis responses and to cope with the responses based on those inferences. [52] reported that a positive framing message may persuade consumers to purchase a product, aside from reminding them about the social attributes of the product. Simultaneously, such framing seems to be a strong marketing tool. [53] revealed that almost 91.7 percent of face advertisements had attracted attention more than no-face advertisements. By incorporating faces and image in advertising message, an organization may avoid the possibility of banner blindness phenomenon [54]. Meanwhile, [16] highlighted that all uppercase letter tagline and an initial letter uppercase tagline can evoke a stronger perception of fear arousal and congruence in environmental threat advertising, when compared to an all lowercase letter tagline. The inclusion of intertextuality is a highly effective method of articulating messages and the ability to affect consumers' emotion [55]. In a separate attempt, [56] suggested that involvement of celebrities is the best way of conveying sustainable message as they can be aspirational role model and more influential than politicians. In Malaysia, consumers can be easily persuaded and think positively when making decisions related with green products [57].

- Parasocial Relationship: [58] signified parasocial relationship as the virtual online relationship formed between online digital celebrities and followers. Such relationships formed between online digital celebrities and followers. Such relationships can make virtual reality more realistic, while enabling them to form pseudo-friendships 
[59]. To date, the emergence of SNS has led organizations to use social media more as an advertising platform [60].

These scholars found that Facebook advertisements have enticed followers of celebrities, including their friends, to purchase advertised products. This relationship is mostly driven by a fashion web celebrity endorser attribute. In line with the findings, the popularity of endorser has formed a new marketing called 'influencer marketing' that works through, brands collaborated with influencers to promote their products [61]. A number of past studies have focused on celebrity endorsers [62-63] then, social influencers can be neither traditional celebrities, such as famous actors athletes, nor are their posts traditional advertisements [64].

Despite the mounting positive results related to parasocial relationships, Russians customers still have high negative perception towards advertisement [65]. In this sense, the endorsers need to care about their physical attraction in order to build effective advertisement [66]. Throughout effective advertisement, parasocial relationships have a huge potential for brand evaluation entailed with value equity, relationship equity, and brand equity [67, 68]. Following this notion, businesses can deliberate information and even more importantly, balance the emotion link between the two parties. To this end, parasocial relationships can diminish the misunderstanding and skeptical about digital ads, as well as the brand itself [68].

In the Malaysian context, many are extrinsically motivated to practice sustainable consumption as they are mostly influenced by their related need. They practice sustainable consumption to feel connected with other members [69]. Drawing on prior studies [70-71], promoting general sustainable product through endorser share a positive correlation.

- Sources Credibility: Sources credibility reflects advertising value, and the advertisement accumulated from the evaluation discussed by peer on social media [72]. The performance of these digital sources appears to be more credible, when compared to traditional media [72]. The credibility of blogs seemed to positively affect the attitude towards the blog [73]. [74] incorporated source credibility to reflect the antecedents of social influence in s-commerce. This study reported a positive outcome by enhancing the understanding of peer influence on consumers in this context [74]. Social diversity among people emanates the sharing practice and simultaneously enhance the perceived credibility of the brand [75]. In line with this, Malaysia is shaped based on collectivistic values by aims and mutual effort depicted based on group support with respect to sustainability value [76].

\section{Theoretical Framework}

Figure 1 illustrates the theoretical framework of this study. It posits that persuasion knowledge serves as an independent variable that influences sustainable fashion consumption.
Meanwhile, parasocial relationship and sources credibility function as the moderating variables. The figure 1 shown the theoretical framework for sustainable fashion consumption.

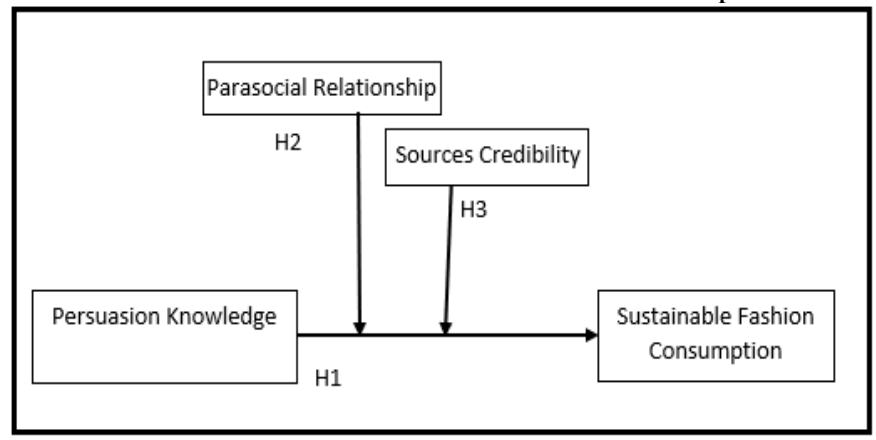

Fig. 1.Proposed Theoretical Framework for Sustainable Fashion Consumption Study

The hypotheses developed for this study are:

- H1: Persuasion knowledge has a positive impact on sustainable fashion consumption.

- H2: Parasocial relationship has a moderating impact on persuasion knowledge and sustainable fashion consumption.

- H3: Sources credibility has a moderating role on persuasion knowledge and sustainable fashion consumption.

\section{RESEARCH METHODOLOGY}

This study will adopt the quantitative method and PLS SEM to carry on the analysis. The questionnaires will be distributed to users of social media platform in Malaysia. The study outcomes will be revealed in the upcoming publication.

\section{DATA ANALYSIS}

Since future research will rely on a survey and experimental method, the respondent involve in this data analysis is from those who have experience purchasing sustainable fashion items. The future respondents will be the customers of sustainable fashion. It is easier to reach them as sustainable fashion is wider and comprise of several myriad term including environmentally friendly, recycled, upcycled, collaboration practice, ethical and slow fashion term and custom made [1]. Remarkably, it is important to reach a real buyer of this positive product as it will influence the result and final conclusion for the study.

In the meantime, the two advertisement with the inclusion and exclusion of real personality or public figures and influencers popular in Malaysia will be used as the stimuli in the SNS digital advertisement. The results of these analysis will reveal the effectiveness of social credibility and parasocial relationship in influencing sustainable fashion consumption.

\section{CONCLUSION AND DISCUSSION}

This study sought to illustrate digital effective communications (SNS) by focusing on sustainable fashion start-ups. Drawing upon on the PKM as a framework, designers and businesses are expected to get a clear target and persuasion ways on how to promote this positive fashion effectively. 
The integration of two moderating roles (parasocial relationship and sources credibility) will boost the confidence amongst consumers towards this fashion concept. It been proved that, although the sustainable fashion scene in Malaysia is still low but this movement is moving along the words of slowly but surely.n conclusion, all the selected variables have been hypothesized positively. With the implementation of PKM, parasocial relationship, and sources credibility, this study contends that sustainable fashion can be promoted successfully through this digital platform. Notably, SNS advertising has a huge potential to shift the paradigm from traditional advertisement to a new way of digital platform. This platform can reach a wider scope of consumers in Malaysia. The involvement of social influencers and celebrities in Malaysia enables the spread of this sustainable movement. At the same momentum, sustainable fashion players need to prepare a special platform to let consumers participate in sharing session and discussion to provide real feedback from the previous product usage. Hence, collaboration from all parties will outshine the sustainable fashion in future.

\section{LIMITATIONS AND FUTURE PATHWAY}

As with any study, this study has several limitations. First, this study only focused on promoting the broad concept of sustainable fashion. Future research can focus on the specific fashion product, including clothing, jewelry, cosmetics, and car. Second, more research works are required to assess different cultures by involving parasocial relationships and sources credibility on SNS. As Malaysia can be classified as collectivism culture, it may differ in terms of level of acceptance for individualistic culture.

\section{REFERENCES}

1. C. J. Henninger, C. E., Alevizou, P. J., \& Oates, "What is sustainable International Journal, vol. 20, no. 4, pp. 400-416, 2016.

2. L. Siegle, "The eco guide to fast fashion," 2017. [Online]. Available: https:/www.theguardian.com/environment/2017/apr/23/theecoguide-to-fast-fashion. [Accessed: 03-May-2019].

3. C. Dickenbrok and L. F. Martinez, "Communicating green fashion across different cultures and geographical regions," International Review on Public and Nonprofit Marketing, vol. 15, no. 2, pp. 127-141, 2018.

4. E. G. Hansen and S. Schaltegger, "100 per cent organic? A sustainable entrepreneurship perspective on the diffusion of organic clothing," Corporate Governance (Bingley), 2013.

5. M. Mirjalili, K. Nazarpoor, and L. Karimi, "Eco-friendly dyeing of wool using natural dye from weld as co-partner with synthetic dye,' Journal of Cleaner Production, vol. 19, no. 9-10, pp. 1045-1051, 2011.

6. E. Mora, A. Rocamora, and P. Volonté, "On the issue of sustainability in fashion studies," International Journal of Fashion Studies, vol. 1, no. 2, pp. 139-147, 2014.

7. L. Mcneill and R. Moore, "Sustainable fashion consumption and the fast fashion conundrum: Fashionable consumers and attitudes to sustainability in clothing choice," International Journal of Consumer Studies, 2015.

8. M. Brettel, J. C. Reich, J. M. Gavilanes, and T. C. Flatten, "What drives advertising success on facebook? An advertising-effectiveness model: Measuring the effects on sales of 'likes' and other social-network Stimuli," Journal of Advertising Research, vol. 55, no. 2, pp. 162-175, 2015.

9. C. A. Lin and T. Kim, "Predicting user response to sponsored advertising on social media via the technology acceptance model," Computers in Human Behavior, vol. 64, pp. 710-718, 2016.

10. Sustainable Development Goals, "Sustainable Development Goals UNDP in Malaysia, Singapore \& Brunei Darussalam,” 2019. [Online] Available:

http://www.my.undp.org/content/malaysia/en/home/sustainable-devel fashion?," Journal of Fashion Marketing and Management: An

opment-goals.html. [Accessed: 04-Aug-2019].

11. N. E. Landrum, "Stages of corporate sustainability: Integrating the strong sustainability worldview," Organization and Environment, vol. 31, no. 4, pp. 287-313, 2018.

12. K. Jacobs, L. Petersen, J. Hörisch, and D. Battenfeld, "Green thinking but thoughtless buying? An empirical extension of the value-attitude-behaviour hierarchy in sustainable clothing," Journal of Cleaner Production, vol. 203, pp. 1155-1169, 2018.

13. S. Guo, T. M. Choi, and B. Shen, "Green product development under competition: A study of the fashion apparel industry," European Journal of Operational Research, vol. 280, no. 2, pp. 523-538, 2020.

14. D. Atanasova, "Moving Society to a Sustainable Future: The Framing of Sustainability in a Constructive Media Outlet," Environmental Communication, vol. 13, no. 5, pp. 700-711, 2019.

15. S. C. Chu, S. Kamal, and Y. Kim, "Re-examining of consumers' responses toward social media advertising and purchase intention toward luxury products from 2013 to 2018: A retrospective commentary," Journal of Global Fashion Marketing, vol. 10, no. 1, pp. 81-92, 2019.

16. Y. Song and Y. Luximon, "Design for sustainability: The effect of lettering case on environmental concern from a green advertising perspective," Sustainability (Switzerland), vol. 11, no. 5, p. 1333, 2019.

17. B. Guedes, A. C. Paillard-Bardey, and A. Schat, "Improving sustainable fashion marketing and advertising: A reflection on framing message and target audience," International Journal of Market Research, 2018.

18. C. R. Taylor, "A call for more research on 'green' or environmental advertising," International Journal of Advertising, vol. 34, no. 4, pp 573-575, 2015.

19. MATRADE, "Export Prospects For Ethical Fashion Industry," 2017. [Online]. Available: http://www.matrade.gov.my/en/about-matrade/media/press-releases/3 932-export-prospects-for-ethical-fashion-industry. [Accessed: 04-Aug-2019].

20. M. Friestad and P. Wright, "Persuasion Knowledge: Lay People's and Researchers' Beliefs about the Psychology of Advertising," Journal of Consumer Research, vol. 22, no. 1, p. 62, 1995.

21. K. Panic, V. Cauberghe, and P. De Pelsmacker, "Comparing TV ads and advergames targeting children: The impact of persuasion knowledge on behavioral responses," Journal of Advertising, vol. 42, no. 2-3, pp. 264-273, 2013.

22. C. D. Ham, M. R. Nelson, and S. Das, "How to measure persuasion knowledge," International Journal of Advertising, vol. 34, no. 1, pp. 17-53, 2015.

23. M. Friestad and P. Wright, "The Persuasion Knowledge Model: How People Cope with Persuasion Attempts," Journal of Consumer Research, vol. 21, no. 1, p. 1, 1994.

24. M. C. Campbell and A. Kirmani, "Consumers' Use of Persuasion Knowledge: The Effects of Accessibility and Cognitive Capacity on Perceptions of an Influence Agent," Journal of Consumer Research, vol. 27, no. 1, pp. 69-83, 2000.

25. J. Knoll, "Advertising in social media: A review of empirical evidence," International Journal of Advertising, vol. 35, no. 2, pp. 266-300, 2016.

26. Y. K. Dwivedi, G. Kelly, M. Janssen, N. P. Rana, E. L. Slade, and M. Clement, "Social Media: The Good, the Bad, and the Ugly," Information Systems Frontiers, vol. 20, no. 3. pp. 419-423, 2018.

27. W. L. Shiau, Y. K. Dwivedi, and H. S. Yang, "Co-citation and cluster analyses of extant literature on social networks," International Journal of Information Management, vol. 37, no. 5, pp. 390-399, 2017.

28. S. Han, J. Min, and H. Lee, "Building relationships within corporate SNS accounts through social presence formation," Internationa Journal of Information Management, vol. 36, no. 6, pp. 945-962, 2016

29. T. Hennig-Thurau et al., "The impact of new media on customer relationships," Journal of Service Research, vol. 13, no. 3, pp. 311-330, 2010.

30. C. S. kum Tang and Y. Y. W. Koh, "Online social networking addiction among college students in Singapore: Comorbidity with behavioral addiction and affective disorder," Asian Journal of Psychiatry, vol. 25, pp. 175-178, 2017.

31. M. S. Eastin, N. H. Brinson, A. Doorey, and G. Wilcox, "Living in a big data world: Predicting mobile commerce activity through privacy concerns," Computers in Human Behavior, vol. 58, pp. 214-220, 2016

Published By: 
32. Oslo roundtable on sustainable production and consumption, "Oslo roundtable on sustainable production and consumption," 1994. [Online]. Available: http://www.iisd.ca/consume/oslo000.html. [Accessed: 04-May-2019].

33. K. Niinimäki, "Eco-Clothing, consumer identity and ideology,"

34. G. Seyfang, The new economics of sustainable consumption: Seeds of change. London: Palgrave Macmillan, 2011.

35. K. Fletcher, Sustainable fashion and textiles: Design journeys. 2012.

36. T. Jägel, K. Keeling, A. Reppel, and T. Gruber, "Individual values and motivational complexities in ethical clothing consumption: A means-end approach," Journal of Marketing Management, vol. 28, no. 3-4, pp. 373-396, 2012.

37. C. J. Henninger, C. E., Alevizou, P. J., and Oates, C. E. Henninger, P. J. Alevizou, C. J. Oates, and C. J. Henninger, C. E., Alevizou, P. J., \& Oates, "What is sustainable fashion?," Journal of Fashion Marketing and Management: An International Journal, vol. 20, no. 4, pp. 400-416, 2016.

38. A. Brismar, "Seven Forms of Sustainable Fashion," 2019. [Online]. Available:

http://www.greenstrategy.se/sustainable-fashion/seven-forms-of-susta inable-fashion/.

39. H. Poore, "5 ways to help fashion become a force for good. Positive News," 25-Apr-2017.

40. L. Wai Yee, S. H. Hassan, and T. Ramayah, "Sustainability and Philanthropic Awareness in Clothing Disposal Behavior Among Young Malaysian Consumers," SAGE Open, 2016.

41. I. A. Davies and S. Gutsche, "Consumer motivations for mainstream 'ethical' consumption," European Journal of Marketing, vol. 50, no. 7-8, pp. 1326-1347, 2016.

42. F. Harris, H. Roby, and S. Dibb, "Sustainable clothing: Challenges, barriers and interventions for encouraging more sustainable consume behaviour," International Journal of Consumer Studies, vol. 40, no. 3 , pp. 309-318, 2016

43. G. Liobikiene and R. Juknys, "The role of values, environmental risk perception, awareness of consequences, and willingness to assume responsibility for environmentally-friendly behaviour: The Lithuanian case," Journal of Cleaner Production, vol. 112, pp. 3413-3422, 2016.

44. S. Portway, "Climate justice isn't sexy: The double failure of sustainable fashion marketing and activism," Fashion, Style and Popular Culture, vol. 6, no. 1, pp. 49-67, 2019.

45. K. Niinimäki and L. Hassi, "Emerging design strategies in sustainable production and consumption of textiles and clothing," Journal of Cleaner Production, vol. 19, no. 16, pp. 1876-1883, 2011.

46. L. Hoang, "“The 10 commandments of new consumerism.," Business of Fashion, 2016.2 [Online]. Available: https://www.businessoffashion.com/articles/intelligence/the-10-comm andments-of-new-consumerism. [Accessed: 10-May-2019].

47. E. Köhrer and M. Schaffrin, "Fashion made fair," Selvedge, no. 72. p. 77, 2016.

48. J. E. Ha-Brookshire and P. S. Norum, "Willingness to pay for socially responsible products: Case of cotton apparel," Journal of Consumer Marketing, vol. 28, no. 5, pp. 344-353, 2011.

49. V. Reimers, B. Magnuson, and F. Chao, "The academic conceptualisation of ethical clothing: Could it account for the attitude behaviour gap?," Journal of Fashion Marketing and Management, vol. 20, no. 4, pp. 383-399, 2016.

50. A. Biswas and M. Roy, "Green products: An exploratory study on the consumer behaviour in emerging economies of the East," Journal of Cleaner Production, vol. 87, no. 1, pp. 463-468, 2015. Sponsored': Effects of Sponsorship Disclosure on Persuasion Knowledge and Electronic Word of Mouth in the Context of Facebook," Journal of Interactive Marketing, vol. 38, pp. 82-92, 2017.

52. C. Hwang, Y. Lee, S. Diddi, and E. Karpova, "'Don't buy this jacket': Consumer reaction toward anti-consumption apparel advertisement," Journal of Fashion Marketing and Management, vol. 20, no. 4, pp.

53. G. Guido, M. Pichierri, G. Pino, and R. Nataraajan, "Effects of face images and face pareidolia on consumers' responses to print advertising: An empirical investigation," Journal of Advertising Research, vol. 59, no. 2, pp. 219-231, 2019.

54. G. Hervet, K. Guérard, S. Tremblay, and M. S. Chtourou, "Is banner blindness genuine? Eye tracking internet text advertising," Applied Cognitive Psychology, vol. 25, no. 5, pp. 708-716, 2011.

55. N. Ghazal Aswad, "Portrayals of Endangered Species in Advertising: Exercising Intertextuality to Question the Anthropocentric Lens," Environmental Communication, vol. 13, no. 1, pp. 118-134, 2019.

56. P. Hanna, J. Kantenbacher, S. Cohen, and S. Gössling, "Role model advocacy for sustainable transport," Transportation Research Part D: Sustainable Development, vol. 18, no. 3, pp. 150-162, 2010.

51. S. C. Boerman, L. M. Willemsen, and E. P. Van Der Aa, “'This Post Is 435-452, 2016.

Transport and Environment, 2018.

57. T. Booi Chen and L. Teck Chai, "Attitude towards the Environment and Green Products: Consumers' Perspective," Management Science and Engineering, vol. 4, no. 2, pp. 27-39, 2010.

58. J. Cohen, M. B. Oliver, and H. Bilandzic, "The differential effects of direct address on parasocial experience and identification: Empirical evidence for conceptual difference," Communication Research Reports, vol. 36, no. 1, pp. 78-83, 2019.

59. D. H. Shin and F. Biocca, "Explicating user behavior toward multi-screen adoption and diffusion: User experience in the multi-screen media ecology," Internet Research, vol. 27, no. 2, pp. 338-361, 2017.

60. H. J. Gu, O. S. Lee, and M. J. Hong, "The Relationship between SNS addiction tendency, Self assertiveness, Interpersonal problems and in College students," Journal of the Korea Academia-Industrial cooperation Society, vol. 17, no. 4, pp. 180-187, 2016.

61. M. De Veirman, V. Cauberghe, and L. Hudders, "Marketing through instagram influencers: The impact of number of followers and product divergence on brand attitude," International Journal of Advertising, vol. 36, no. 5, pp. 798-828, 2017.

62. J. B. Ford, "What do we know about celebrity endorsement in advertising?," Journal of Advertising Research, vol. 58, no. 1, pp. 1-2, 2018.

63. K. McCormick, "Celebrity endorsements: Influence of a product-endorser match on Millennials attitudes and purchase intentions," Journal of Retailing and Consumer Services, vol. 32, pp. 39-45, 2016.

64. C. Abidin, ““'Aren't these just young, rich women doing vain... Google Scholar," Social Media+ Society, vol. 2, no. 2, p. 2056305116641342, 2016.

65. E. Djafarova and C. Rushworth, "Exploring the credibility of online celebrities' Instagram profiles in influencing the purchase decisions of young female users," Computers in Human Behavior, vol. 68, pp. 1-7, 2017.

66. K. Sokolova and H. Kefi, "Instagram and YouTube bloggers promote it, why should I buy? How credibility and parasocial interaction influence purchase intentions," Journal of Retailing and Consumer Services, 2019.

67. J. E. Lee and B. Watkins, "YouTube vloggers' influence on consumer luxury brand perceptions and intentions," Journal of Business Research, vol. 69, no. 12, pp. 5753-5760, 2016.

68. C. L. Yuan, H. Moon, K. H. Kim, and S. Wang, "The influence of parasocial relationship in fashion web on customer equity," Journal of Business Research, 2019.

69. S. Abdulrazak and F. Quoquab, "Exploring Consumers' Motivations for Sustainable Consumption: A Self-Deterministic Approach," Journal of International Consumer Marketing, vol. 30, no. 1, pp. 14-28, 2018.

70. P. Hanna, J. Kantenbacher, S. Cohen, and S. Gössling, "Role model advocacy for sustainable transport," Transportation Research Part D: Transport and Environment, 2018.

71. M. Y. Kang, Y. Choi, and J. Choi, "The effect of celebrity endorsement on sustainable firm value: evidence from the Korean telecommunications industry," International Journal of Advertising, 2019.

72. M. A. Shareef, B. Mukerji, Y. K. Dwivedi, N. P. Rana, and R. Islam, "Social media marketing: Comparative effect of advertisement sources," Journal of Retailing and Consumer Services, vol. 23, no. 3 pp. 297-327, 2019.

73. D. A. Colton, “Antecedents of consumer attitudes' toward corporate blogs," Journal of Research in Interactive Marketing, vol. 12, no. 1, pp. 94-104, 2018.

74. X. Hu, X. Chen, and R. Davidson, "Social support, source credibility, social influence, and impulsive purchase behavior in social commerce," International Journal of Electronic Commerce, vol. 23, no. 3, pp. 297-327, Jul. 2019.

75. A. Hayat, T., \& Hershkovitz, "The role social cues play in mediating the effect of eWOM over purchasing intentions: An exploratory analysis among university students," Journal of Customer Behaviour vol. 17, no. 3, pp. 173-187, 2018.

76. B. Chekima, S. Chekima, S. A. W. Syed Khalid Wafa, O. A. Igaua, and S. L. Sondoh, "Sustainable consumption: The effects of knowledge, cultural values, environmental advertising, and demographics," International Journal of Sustainable Development and World Ecology, vol. 23, no. 2, pp. 210-220, 2016.

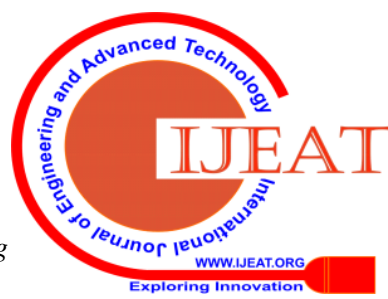




\section{AUTHORS PROFILE}

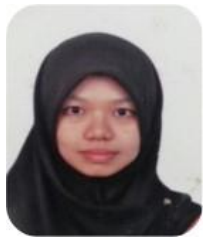

Nornajihah Nadia Hasbullah, Ph.D. Candidate, Azman Hashim International Business School (AHIBS), Universiti Teknologi Malaysia (UTM), $81310 \quad$ Skudai, Johor, Malaysia, najihahnadya@yahoo.com.my

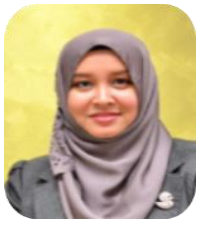

Zuraidah Sulaiman, Senior Lecturer, Azman Hashim International Business School (AHIBS), Universiti Teknologi Malaysia (UTM), 81310 Johor Skudai, Johor, Malaysia.

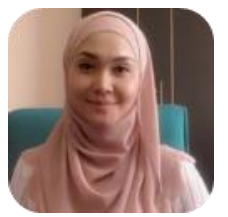

Adaviah Mas'od, Senior Lecturer, Azman Hashim International Business School (AHIBS), Universiti Teknologi Malaysia (UTM), 81310 Johor Skudai, Johor, Malaysia. 